\title{
A long-term evaluation of a training program on breaking bad news in pediatric neurosurgery: a pilot study
}

\author{
Marc Zanello, MD, MSc, ${ }^{1-3}$ Thomas Baugnon, MD, ${ }^{2,4}$ Alexandre Roux, MD, MSc, ${ }^{1-3}$ and \\ Federico Di Rocco, MD, PhD 5 ,6
}

\begin{abstract}
1Department of Neurosurgery, Sainte-Anne Hospital, Paris; ${ }^{2}$ Sorbonne Paris Cité, Paris Descartes University, Paris; ${ }^{3}$ nserm U894, IMA-Brain, Centre Psychiatrie et Neurosciences, Paris; ${ }^{4}$ Anaesthesiology Department, Assistance Publique-Hôpitaux de Paris, Hôpital Universitaire Necker, Paris; ${ }^{5}$ Pediatric Neurosurgery, Hôpital Femme Mère Enfant, Hospices Civiles de Lyon and University Claude Bernard Lyon 1, Bron Cedex; and ${ }^{6}$ Reference Center for Craniosynostosis, Inserm 1033, Lyon, France
\end{abstract}

OBJECTIVE Breaking bad news is a difficult task in medical practice. Several breaking-bad-news training programs have been proposed. However, long-term results of such training have rarely been investigated. The aim of this study was to compare the short- and long-term evaluations by young neurosurgeons of a training program for breaking bad news to patients and their parents.

METHODS Between 2012 and 2015, pediatric neurosurgery residents participated in a training day on breaking bad news in pediatric neurosurgery with professional actors. A personal debriefing, followed by a theoretical session, completed the training. Immediate feedback was evaluated through a survey administered at the end of the day. Long-term results were explored via an online form sent at least 3 years after the training completion.

RESULTS Seventeen participants from 9 different countries were interviewed. Their immediate feedback confirmed their interest. For $71 \%$ of them, the program was very interesting, and $77 \%$ were extremely satisfied or very satisfied. All trainees wanted more training sessions. At a mean of 4.5 years of follow-up (range 3-6 years), $71 \%$ of the trainees fully remembered the session. Most of them (86\%) reported a positive impact of the training on their career. Only $21 \%$ had another training session on breaking bad news during their residency. At long-term analysis, fewer trainees considered the duration of the training to have been sufficient $(p=0.044)$.

CONCLUSIONS Breaking-bad-news training has a positive long-term educational impact even several years later. Such a training program should be implemented into pediatric neurosurgery residency.

https://thejns.org/doi/abs/10.3171/2019.12.PEDS19554

KEYWORDS simulation training; patient simulation; interpersonal relations; intraoperative complications; pediatrics; role-playing

I NTERPERSONAL and communication skills to recognize and deal with social and cultural problems represent a key domain in medical education, and the importance of acquiring these skills has recently been reinforced.,20 This need for effective learning of communication skills is particularly important in pediatric specialties, as both the patient and family should be considered. Pediatric neurosurgeons face severe situations; brain tumor is the second most common oncological pathology in the pediatric population, with an increasing incidence in the past few years. ${ }^{23}$ Moreover, the frequency of complex malformations is high in this age group. Head injuries are a leading cause of mortality and severe morbidity. In such a context, delivering bad or difficult news to the families requires an appropriate training session..$^{14,28}$

Family and patient satisfaction and reaction in the face of a possible complication are strongly related to both medical information and nonverbal communication. ${ }^{12}$ Numerous interventions aiming to improve the communication competency and confidence of physicians in breaking bad news have been proposed. The need for intelligible, appropriate, and truthful information to be delivered further supports the necessity of dedicated educational training programs concerning pre- and postoperative communication. $.^{19} \mathrm{Sim}-$ ulation-based interpersonal communication skills training seems to have satisfied participants and teachers immedi- 
ately after the training. ${ }^{11}$ Actors have played validated scenarios during which trainees, residents, or fellows have to deal with complex real-life situations. This simulation modality is an increasing part of training in different medical specialties in different countries. ${ }^{11,28}$

The goal of training is to improve trainees' autonomy during their career. However, long-term results of simulation-based interpersonal communication skills training remain scarcely explored. ${ }^{14}$

The aim of this study was to evaluate the long-term benefits of a dedicated simulation-based training performed several years earlier. In addition, the trainees' reactions immediately after the training session were compared with their long-term reactions.

\section{Methods}

The institutional review board of Necker-Enfants Malades Hospital approved this study. This study followed the Standards for Quality Improvement Reporting Excellence 2.0 (SQUIRE 2.0) guidelines. ${ }^{22}$

\section{Interventions}

\section{Simulation-Based Interpersonal Communication Skills Training Program}

The characteristics of the trainees and the organization of training sessions are described in Table 1 and Fig. 1. Two professional actors representing the parents of patients were trained through scenarios elaborated by a neurosurgeon and an anesthesiologist. There were 3 different scenarios: hydrocephalus secondary to meningitis in need of a ventriculoperitoneal shunt, hydrocephalus related to aqueductal stenosis requiring a ventriculocisternostomy, and an intraventricular hemorrhage needing external cerebrospinal fluid drainage.

Each resident was randomly assigned to one of these scenarios. Each scenario was divided into two main parts: first, the announcement of the diagnosis and the need for a surgical procedure (for instance, hydrocephalus requiring an endoscopic third ventriculostomy) and, later, the announcement of a surgical complication (bleeding during the endoscopic third ventriculostomy).

All trainees had given their consent to participate in the simulation at the beginning of their internship. The training session occurred during the 6-month pediatric neurosurgery rotation at least 2 months after the beginning of the rotation. The simulation took place at the hospital in a room fully equipped with cameras and sound registration. Its duration was 30 minutes. A psychologist and a neuropsychologist observed the interactions with the actors to analyze the verbal and nonverbal communication skills of the trainees. After the training session, 1-hour feedback on the session with the help of the videotape of the performance was provided by a team comprising a senior neurosurgeon, a senior neuro-anesthesiologist, a psychologist, a neuropsychologist, and the actors who simulated the patient's parents. Training was performed in a single day to ensure a maximum rate of acceptance and avoid interfering with the daily clinical practice. A common feedback session was also organized with all participants in a 6-month rotation. It consisted of a presentation on
TABLE 1. Population characteristics of residents who underwent breaking-bad-news training

\begin{tabular}{|c|c|}
\hline Characteristic & $\begin{array}{c}\text { No. of } \\
\text { Participants (\%) }\end{array}$ \\
\hline \multicolumn{2}{|l|}{ Sex } \\
\hline Male & $9(52.9)$ \\
\hline Female & $8(47.1)$ \\
\hline \multicolumn{2}{|l|}{ Age, yrs } \\
\hline $25-30$ & $3(17.6)$ \\
\hline $30-35$ & $6(35.3)$ \\
\hline$>35$ & $8(47.1)$ \\
\hline \multicolumn{2}{|l|}{ Country of origin } \\
\hline Algeria & $2(11.8)$ \\
\hline Brazil & $1(5.9)$ \\
\hline Chile & $1(5.9)$ \\
\hline France & $8(47.1)$ \\
\hline Italy & $1(5.9)$ \\
\hline Palestine & $1(5.9)$ \\
\hline Saudi Arabia & $1(5.9)$ \\
\hline Spain & $1(5.9)$ \\
\hline Tunisia & $1(5.9)$ \\
\hline \multicolumn{2}{|l|}{ Position at beginning of study } \\
\hline 1st third of surgical internship program (0-18 mos) & $1(5.9)$ \\
\hline $\begin{array}{l}\text { 2nd third of surgical internship program (>18-42 } \\
\text { mos) }\end{array}$ & $7(41.2)$ \\
\hline $\begin{array}{l}\text { Last third of surgical internship program (>42 } \\
\text { mos) }\end{array}$ & $9(52.9)$ \\
\hline \multicolumn{2}{|l|}{ Position at end of study } \\
\hline Resident & $1(5.9)$ \\
\hline Fellow & $7(41.2)$ \\
\hline Attending physician & $5(29.4)$ \\
\hline Chief physician & $4(23.5)$ \\
\hline \multicolumn{2}{|l|}{ Practice at end of study } \\
\hline Exclusively pediatric neurosurgery & $5(29.4)$ \\
\hline $\begin{array}{l}\text { Mixed pediatric \& adult neurosurgery (mostly } \\
\text { children) }\end{array}$ & $1(5.9)$ \\
\hline $\begin{array}{l}\text { Mixed pediatric \& adult neurosurgery (mostly } \\
\text { adults) }\end{array}$ & $3(17.6)$ \\
\hline Exclusively adult neurosurgery & $8(47.1)$ \\
\hline
\end{tabular}

verbal and nonverbal communication, on the principles of how to deliver bad news from the psychologist's point of view, and from a senior neurosurgeon detailing the French version of the SPIKES (EPICES) ${ }^{27}$ protocol (further described in Discussion).

\section{Trained Population}

All residents who rotated for a 6-month period in the pediatric neurosurgery department during the years 2012 and 2015 were invited to participate in the 1-day training program. None of the invited residents refused to participate. The training program took place after at least 2 months of the 6-month rotation in pediatric neurosurgery. The French residents were part of a larger neurosurgery program called the Diplôme d'Études Spécialisées de Neurochirurgie.

All trainees were fluent in French. All nonnative speak- 

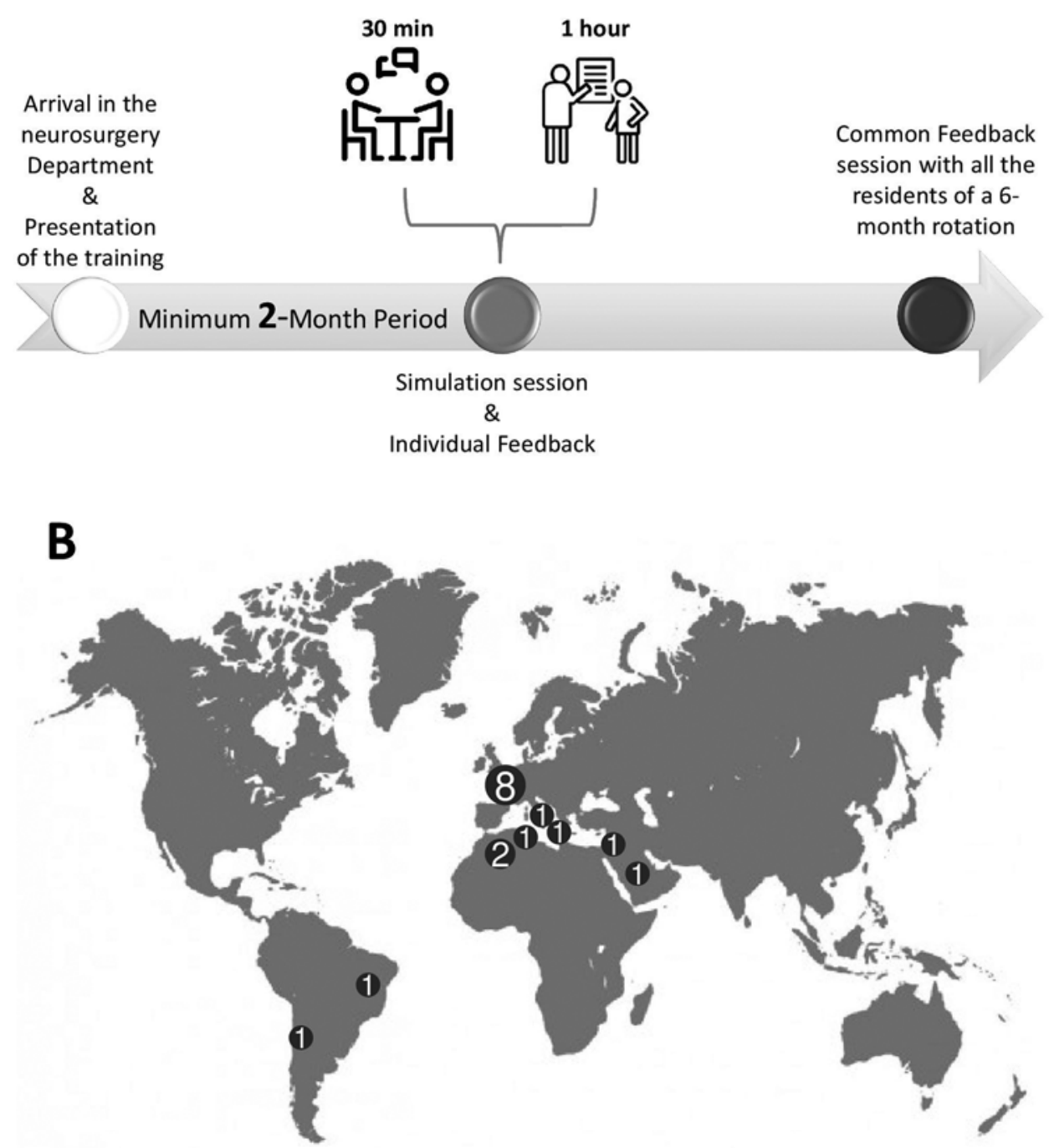

FIG. 1. Schedule of the training session $(\mathbf{A})$ and map showing the countries of origin of the trained population $(\mathbf{B})$. $\min =$ minutes.

ers had successfully acquired the B2 level of the following accredited degrees in order to work in French hospitals: French assessment test (Test d'évaluation du français), French language test (Test de connaissance du français), diploma in French language studies (Diplôme d'Études de Langue française), or advanced diploma in the French language (Diplôme approfondi de langue française). ${ }^{15}$

\section{Intervention Analysis}

Evaluation of Immediate Results

The trainees were asked to complete a feedback survey at the end of their training session. Supplementary Table 1 shows the immediate feedback survey. The questionnaire, designed by two experts (a senior neurosurgeon and a senior anesthesiologist), included 8 items with different Likert scales (1-5 and 1-7), binary answers (yes/no), and short answers.

\section{Evaluation of Long-Term Results}

An online survey was created using a Google Doc Form by two senior neurosurgeons. Supplementary Table 2 shows the long-term feedback survey. The questionnaire was sent to each participant by mail during December 2018 , at least 3 years after completion of the training. Two reminders were sent to ensure a maximal answer rate.

\section{Statistical Analysis}

Categorical data are reported as percentages. Cohen's kappa coefficient $(\kappa)$ was used to measure interrater agreement; $\mathrm{p}<0.05$ was considered statistically significant. Statistical analyses were carried out on the following 5 comparable items: overall satisfaction, recommendation of this training to colleagues, evaluation of the training duration, impact of this training in professional life, and evaluation of the training's pedagogy. Statistical analyses 
were performed using JMP software (version 13.2.0, SAS Institute Inc.).

\section{Results \\ Trained Population}

The characteristics of the trainees are described in Fig. 1 and Table 1 . The trained population consisted of 17 residents ( 9 males and 8 females). The residents were mostly between 25 and 30 years of age and came from 9 different countries ( 8 from France). At the time of the long-term analysis, most were neurosurgeons in an adult neurosurgical practice as fellows. At the time of the long-term survey, the non-French trainees had returned to their countries of origin.

\section{Immediate Feedback Survey}

Immediately after the training, most trainees found the training to be interesting (71\%, very interesting; $23 \%$, interesting; and 6\%, no opinion). Most trainees were satisfied with the training session: $12 \%(\mathrm{n}=2)$ were extremely satisfied, $65 \%(\mathrm{n}=11)$ were very satisfied, $18 \%(\mathrm{n}=3)$ were satisfied, and $5.9 \%(\mathrm{n}=1)$ had no opinion. In particular, the benefit, duration, organization, usefulness, and atmosphere of the training session were judged very good or good by all except 3 trainees. Only 1 trainee considered the organization unsatisfactory. Although $29.4 \%(n=5)$ of the trainees were initially reluctant to participate in the program, all of them, at the end of the training session, wanted this type of educational training to be repeated. When asked whether they would have recommended the program to their fellow trainees after having passed it, $35 \%(\mathrm{n}=6)$ fully agreed, $47 \%(\mathrm{n}=8)$ agreed, and $18 \%$ $(n=3)$ moderately agreed. The training session was considered useful for simulating the reflection on the patientphysician relationship and influenced the habits of $82 \%$ (n $=14$ ) of the trainees (Table 2). Of note, the senior neurosurgeon who spearheaded the training session noticed an improvement in participants' abilities to break bad news during the end of their 6-month rotation.

\section{Long-Term Survey}

The long-term survey was completed by $82 \%(n=14)$ of the trainees: 2 were trained in 2015, 5 in 2014, 5 in 2013, and 2 in 2012. The mean follow-up was $4.5 \pm 0.9$ years. Only the trainees who responded to the long-term survey were considered for the long-term results (Table 2).

Seventy-one percent $(n=10)$ of the trainees fully remembered the 1-day formation. All except 1 trainee $(93 \%$ $[\mathrm{n}=13])$ found the duration of the training to be appropriate or very appropriate. Eighty-six percent $(n=12)$ of the cohort found the pedagogic methodology adapted. The mean interactivity of the formation on a scale of 10 was of $8.9 \pm 0.9$. All trainees $(100 \%[n=14])$ agreed or fully agreed recommending this training to colleagues. This teaching met the vast majority of the trainees' expectations $(93 \%[\mathrm{n}=13])$. All but 1 trainee $(93 \%[\mathrm{n}=13])$ found that the training had helped them in their later medical consultations. For $36 \%(n=5)$ of the trainees, it helped to deal with the patients' parents; for $36 \%(\mathrm{n}=5)$, it helped to not reproduce identified pitfalls; for $21 \%(\mathrm{n}=3)$, it im- proved their self-knowledge; and for 7\% ( $\mathrm{n}=1)$, the training added significant value to their residency.

All but one of the trainees $(93 \%[n=13])$ were interested in having further communication training exercises, but only $21 \%(\mathrm{n}=3)$ benefited from other formations on breaking bad news in their neurosurgical residency. Indeed, although the majority of the respondents did not exclusively practice pediatric neurosurgery $(64 \%$ [ $=$ 9]), $93 \%(\mathrm{n}=13)$ had been in a situation comparable to the simulated scenario, and $86 \%(n=12)$ thought that the training had a positive or highly positive impact on their professional career. Fifty-seven percent $(\mathrm{n}=8)$ of participants called for an increased frequency of this type of training throughout residency, $21 \%(n=3)$ desired a training session that lasted longer than 1 day, $14 \%(\mathrm{n}=$ 2 ) wanted written recommendations, and $7 \%(\mathrm{n}=1)$ proposed computer-based simulations.

\section{Statistical Analysis}

The statistical analyses are detailed in Fig. 2.

We observed a certain consistency between the two periods. In both cases, the evaluation of the training was positive. Concerning the overall satisfaction of the trainees, an increase in the "fully agree" rate was found: $42.9 \%$ at the end of follow-up versus $14.3 \%$ immediately after the training $(p=0.243)$. At the end of follow-up, the "fully agree" rate concerning recommendation of the training to other neurosurgeons increased to $64.3 \%$ versus $35.3 \%$ immediately after the training $(p=0.254)$.

However, it should be noted that the "fully agree" rate of the evaluation of the training's duration showed a significant decrease at $21.4 \%$ at the end of follow-up versus $52.9 \%$ immediately after the training $(\mathrm{p}=0.044)$.

\section{Discussion}

To date, this study is the first to investigate long-term results of a dedicated breaking-bad-news training program in pediatric neurosurgery. Several key findings can be pointed out. 1) The immediate satisfaction of the trainees was high, despite initial mixed feelings. 2) All trainees recommended this training after passing it. 3) Most did not benefit from any other simulation-based learning during their residencies. 4) Long-term results showed a high degree of satisfaction and usefulness even several years later. 5) The young neurosurgeons requested more frequent training, especially after some years of active practice.

\section{Interpretation}

The patient's satisfaction and reaction in case of surgical complications are strongly related to the medical discourse and nonverbal communication. ${ }^{12}$ Effective skills in communication are indeed needed by neurosurgeons who are faced daily with complex and dreadful situations. . $^{10,17,24}$ The need for appropriate communication is even more important in pediatric neurosurgery due to the fact that both the patient and their parents are involved. ${ }^{26}$ Various scientific societies have now incorporated strong communication skills in their recommendations,, 21 including the Teacher College of the French Society of Neurosurgery 
TABLE 2. Short-term and long-term survey results

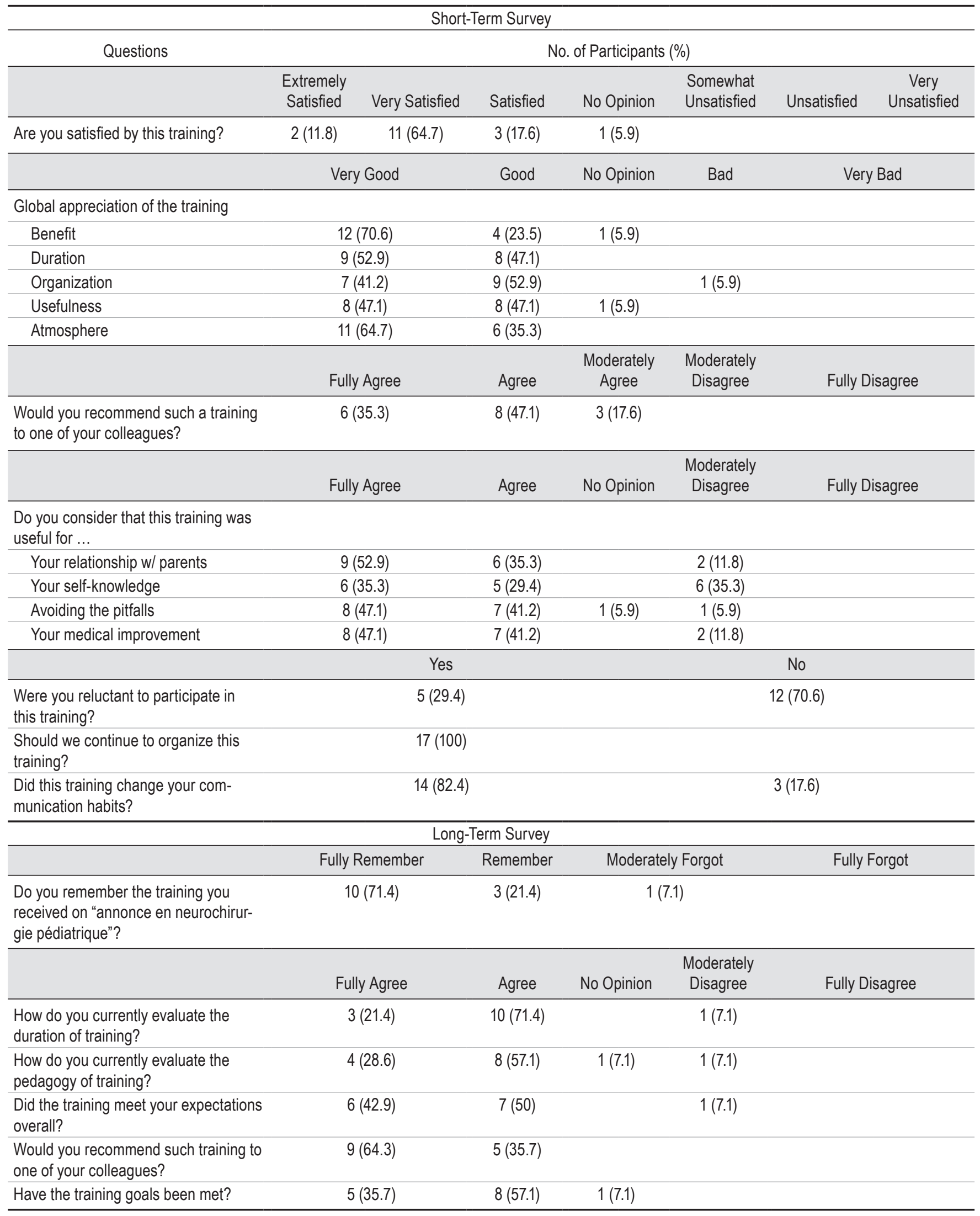




\section{» CONTINUED FROM PAGE 674}

\section{TABLE 2. Short-term and long-term survey results}

\begin{tabular}{|c|c|c|c|c|c|}
\hline \multicolumn{6}{|c|}{ Long-Term Survey (continued) } \\
\hline & Fully Agree & Agree & No Opinion & $\begin{array}{l}\text { Moderately } \\
\text { Disagree }\end{array}$ & Fully Disagree \\
\hline Was the training as you expected? & $6(42.9)$ & $7(50)$ & $1(7.1)$ & & \\
\hline $\begin{array}{l}\text { Did the training help you in your medi- } \\
\text { cal consultations? }\end{array}$ & $5(35.7)$ & $8(57.1)$ & & $1(7.1)$ & \\
\hline $\begin{array}{l}\text { Would you be interested in another } \\
\text { training of this kind? }\end{array}$ & $5(35.7)$ & $7(50)$ & $1(7.1)$ & & $1(7.1)$ \\
\hline $\begin{array}{l}\text { Have you ever been in real life in a } \\
\text { situation comparable to that simulated } \\
\text { in the training? }\end{array}$ & $9(64.3)$ & $4(28.6)$ & & $1(7.1)$ & \\
\hline $\begin{array}{l}\text { Do you think this training has had an } \\
\text { impact in your professional work? }\end{array}$ & $5(35.7)$ & $7(50)$ & $2(14.3)$ & & \\
\hline
\end{tabular}

On a scale of 10 , how do you evaluate

the interactivity of the formation?

\begin{tabular}{cc}
\hline 1 & \\
\hline 2 & \\
\hline 3 & \\
\hline 4 & \\
\hline 5 & $1(7.1)$ \\
\hline 6 & $4(28.6)$ \\
\hline 7 & $5(35.7)$ \\
\hline 8 & $4(28.6)$ \\
\hline 9 &
\end{tabular}

Do you consider that this training was

useful for ...

\begin{tabular}{lc} 
Your relationship w/ parents? & $5(35.7)$ \\
Your self-knowledge? & $3(21.4)$ \\
\hline Avoiding the pitfalls? & $5(35.7)$ \\
Your medical improvement? & $1(7.1)$ \\
\hline How can we improve the training? & $3(21.4)$ \\
\hline Longer time & $8(57.1)$ \\
\hline $\begin{array}{l}\text { Increased frequency } \\
\text { Delivering recommendations on } \\
\text { paper }\end{array}$ & $2(14.3)$ \\
\hline Computer-based simulation & $1(7.1)$ \\
\hline Have you had other training using \\
$\begin{array}{l}\text { actor-based simulation for breaking bad } \\
\text { news in neurosurgery? }\end{array}$ \\
Yes in pediatric neurosurgery \\
Yes in adult neurosurgery \\
Yes in adult \& pediatric neurosurgery \\
No
\end{tabular}

(Collège des Enseignants de la Société Française de Neurochirurgie). Despite these academic recommendations and patient advocacy associations' wishes, the teaching of communication skills in pediatric neurosurgery is rare. ${ }^{11}$ One classic limitation of all breaking-bad-news training was the absence of any investigation of long-term results.
This study emphasized the positive role of a single day of breaking-bad-news teaching during neurosurgical residency. Interestingly, the value of this training was confirmed even several years after the training completion, and the impact of the training on professional life even increased at the end of follow-up. The training duration that was ini- 


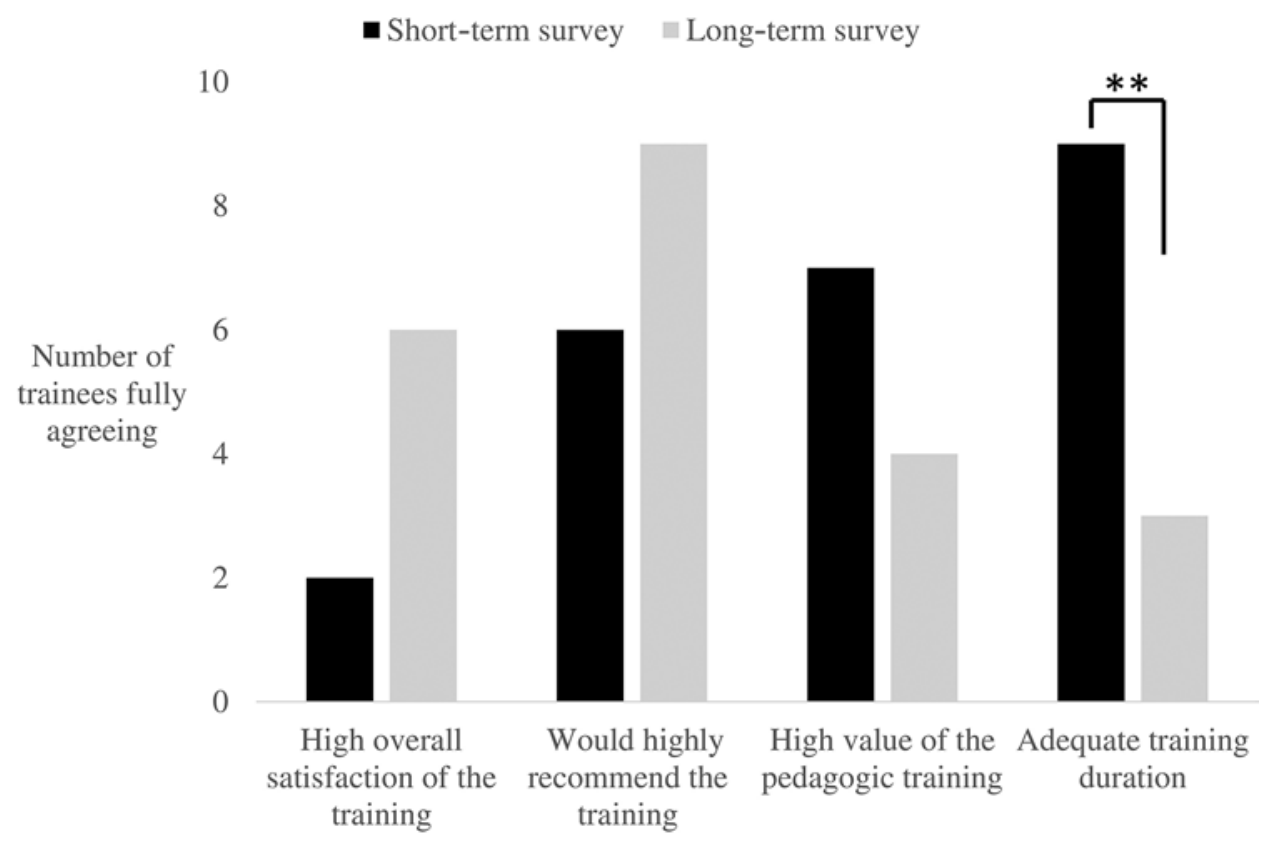

FIG. 2. Number of "fully agree" answers to the 5 comparable items immediately after the training (short-term survey) and at the end of follow-up (long-term survey). Asterisks indicate a significant difference between short-term and long-term answers $(p<0.05)$.

tially judged as sufficient by the trainees was finally reassessed as too short some years later, highlighting the need for increased frequency of these training sessions. Despite the professional experience they had gained, the need of training for breaking bad news appeared to them even more essential.

Several frameworks for bad or difficult news delivery exist. Although none of them are specific, they can be applied to pediatric neurosurgery. SPIKES is one of the most widely used of these frameworks. It proposes 6 steps to improve breaking bad news. These steps, explaining the acronym, are: 1) Setting up the interview, 2) assessing the patient's Perception, 3) obtaining the patient's Invitation, 4) giving Knowledge and information to the patient, 5) addressing the patient's Emotions with empathic responses, and 6) Strategy and Summary. ${ }^{4}$ SPIKES has been translated into many languages and incorporated into numerous residency programs. ${ }^{27}$ Japanese oncologists designed another framework: the SHARE protocol. It has 4 steps: 1) Setting up a supportive environment for the interview, 2) considering How to deliver the bad news, 3) discussing various Additional information that patients would like to know, and 4) providing REassurance and addressing patients' emotions with empathic responses. As visible in the acronym, the reassurance step is particularly highlighted in the SHARE framework due to the fact that this step is important for the patient and difficult for the physician.7,25

The impact of breaking-bad-news training on a physician's communication skills is now well established, in particular in oncology. ${ }^{6-8,16}$ The aim of breaking-bad-news training is to produce long-lasting competence. However, the literature is lacking for long-term evaluations after training completion. To the best of our knowledge, the only study dealing with the long-term effect of breakingbad-news training is a study done for internists published in French. ${ }^{13}$ This interesting study shed light on the effectiveness of breaking-bad-news training for theoretical examinations even 2 years after the end of training. No effect was retrieved concerning a real-life simulation; the trained residents did not perform significantly better than control residents during Objective Structured Clinical Examination 3 months after communication training. Two principal factors could explain this result. First, the duration of the training was probably too short. Second, the assessment grid based on the work by Alexander et al. was not perfectly suited to evaluate the results of Objective Structured Clinical Examination. ${ }^{2}$ The best evaluation remains patient evaluation. ${ }^{25}$ It seems that an increased duration and the frequency of breaking-bad-news training are required to produce clinical effective progress; it was the request of $78 \%$ of the participants in the current study. However, our study showed that even a single day of training could provide long-lasting satisfaction to trainees; the implementation of breaking-bad-news training should not be discouraged by limited time constraints.

Another facet of physician-patient interaction is nonverbal communication. Nonverbal communication is defined as behavior without linguistic content. The role of nonverbal behavior has been less frequently explored than verbal communication but has proven to be helpful for patients, even after several months. ${ }^{3,12,18}$ It seemed of paramount interest to train residents in both verbal and nonverbal communication to improve patient care..$^{28}$ In the context of residents coming from several countries and whose mother language was not French, the feedback of the resident's nonverbal communication was also extremely informative.

\section{Limitations to the Study}

Due to the pilot nature of this study, several limitations 
can be pointed out, and we only mentioned the most significant of these. There was a small number of participants enrolled in a single university academic neurosurgery department without a control group. The training's impact on the participants' abilities to break bad news was not evaluated through dedicated scores. The answer rate to the longterm survey was not complete. The participant's recall of the event was possibly limited. Separation of evaluation from the coordinators and teachers of the course would improve the objectivity of the trainees' answers. A validated measure of evaluation and assessment should be sought or developed over time. Professional consultation with experts in education and psychology could add important additional expertise. Nevertheless, the heterogeneity of the trainees' background-coming from several countries with different levels of surgical education-and the consistency of their answers underlined the lack of efficient communication training in neurosurgery residency despite the complexity of the specialty (potential high morbidity and mortality in the pediatric neurosurgical population).

\section{Perspectives}

The sustained effect of the short training depicted in this study calls for the incorporation of training in breaking bad news in neurosurgical education programs. If multiple sessions with specialized experts likely represent the gold standard, more limited but realistic useful means do exist, such as student peer teaching or serious games. ${ }^{9,29}$

\section{Conclusions}

This study points out the high immediate and longterm effects of a formation dedicated to breaking bad news in pediatric neurosurgery. The vast majority of the trainees remembered the training and felt helped by this formation, even several years after its completion. This sustained effect calls for more training in communication in neurosurgery. Interestingly, 59\% of the cohort were not from France. Thus, our study sheds light on the worldwide lack of training in communication during neurosurgical residencies. Larger studies are required to strengthen the conclusions of this study and to define gold standards for teaching and evaluating communication and interaction skills in neurosurgery. These gold standards are lacking; their definitions represent a challenging but important issue to solve..$^{5}$

\section{Acknowledgments}

We would like to thank (in alphabetical order): Aymeric Amelot, Arthur André, Caroline Apra, Kevin Beccaria, Houda Belmabrouk, Sandro Benichi, Carlos Bennett, Mohamed-Abdelatif Boukebir, Marie Bourgeois, Marina Brigui, Anaïs Chivet, Mariette Delaitre, Aurelia Diaz, Kim Giraudat, Catherine Horodyckid, Johan Pallud, Leslie Pamphile, Giovanna Paternoster, Tatiana Protzenko, Eric Robles, Maxime Ros, Christian Sainte-Rose, Bandar Tammar, Michel Zerah, and Jawad Ziyadeh.

\section{References}

1. Accreditation Council for Graduate Medical Education: Common Program Requirements. Chicago: ACGME, 2017, p 28 (https://www.acgme.org/What-We-Do/Accreditation/
Common-Program-Requirements) [Accessed January 8, 2020]

2. Alexander SC, Keitz SA, Sloane R, Tulsky JA: A controlled trial of a short course to improve residents' communication with patients at the end of life. Acad Med 81:1008-1012, 2006

3. Ambady N, Koo J, Rosenthal R, Winograd CH: Physical therapists' nonverbal communication predicts geriatric patients' health outcomes. Psychol Aging 17:443-452, 2002

4. Baile WF, Buckman R, Lenzi R, Glober G, Beale EA, Kudelka AP: SPIKES - a six-step protocol for delivering bad news: application to the patient with cancer. Oncologist 5:302-311, 2000

5. Del Piccolo L, Finset A: Assessment of nonverbal communication in clinical encounters: many methodological approaches, but no gold standard. Patient Educ Couns 86:279-280, 2012

6. Fallowfield L, Jenkins V, Farewell V, Saul J, Duffy A, Eves R: Efficacy of a Cancer Research UK communication skills training model for oncologists: a randomised controlled trial. Lancet 359:650-656, 2002

7. Fujimori M, Shirai Y, Asai M, Kubota K, Katsumata N, Uchitomi Y: Effect of communication skills training program for oncologists based on patient preferences for communication when receiving bad news: a randomized controlled trial. J Clin Oncol 32:2166-2172, 2014

8. Goelz T, Wuensch A, Stubenrauch S, Ihorst G, de Figueiredo $\mathrm{M}$, Bertz H, et al: Specific training program improves oncologists' palliative care communication skills in a randomized controlled trial. J Clin Oncol 29:3402-3407, 2011

9. Gorbanev I, Agudelo-Londoño S, González RA, Cortes A, Pomares A, Delgadillo V, et al: A systematic review of serious games in medical education: quality of evidence and pedagogical strategy. Med Educ Online 23:1438718, 2018

10. Haines SJ: How to choose your neurosurgeon. Pract Neurol 10:2-3, 2010

11. Harnof S, Hadani M, Ziv A, Berkenstadt H: Simulationbased interpersonal communication skills training for neurosurgical residents. Isr Med Assoc J 15:489-492, 2013

12. Henry SG, Fuhrel-Forbis A, Rogers MAM, Eggly S: Association between nonverbal communication during clinical interactions and outcomes: a systematic review and meta-analysis. Patient Educ Couns 86:297-315, 2012

13. Ibrahim T, Maalouly G, Nemr E, Haddad E, Yazbeck C, Haddad F: Étude préliminaire des effets à court et long terme d'un dispositif de formation à la communication d'une mauvaise nouvelle. Pédagogie Médicale 14:187-201, 2013

14. Johnson J, Panagioti M: Interventions to improve the breaking of bad or difficult news by physicians, medical students, and interns/residents: a systematic review and meta-analysis. Acad Med 93:1400-1412, 2018

15. Jolion JM, Dubeaupuis J: Diplôme de formation médicale spécialisée et diplôme de formation médicale spécialisée approfondie. Paris: Ministère de l'Enseignement supérieur, de la Recherche et de l'Innovation, 2013 (https://www. enseignementsup-recherche.gouv.fr/pid20536/bulletinofficiel.html?cid_bo=67133\&cbo=1) [Accessed January 8, 2020]

16. Liénard A, Merckaert I, Libert Y, Bragard I, Delvaux N, Etienne AM, et al: Is it possible to improve residents breaking bad news skills? A randomised study assessing the efficacy of a communication skills training program. Br J Cancer 103:171-177, 2010

17. Manning BT, Ahn J, Bohl DD, Mayo BC, Louie PK, Singh K: Spine surgeon selection criteria: factors influencing patient choice. Spine (Phila Pa 1976) 41:E814-E819, 2016

18. Mast MS: On the importance of nonverbal communication in the physician-patient interaction. Patient Educ Couns 67:315-318, 2007 
19. Monden KR, Gentry L, Cox TR: Delivering bad news to patients. Proc Bayl Univ Med Cent 29:101-102, 2016

20. Nasca TJ, Philibert I, Brigham T, Flynn TC: The next GME accreditation system - rationale and benefits. N Engl J Med 366:1051-1056, 2012

21. National Institute for Health and Care Excellence: Patient Experience in Adult NHS Services: Improving the Experience of Care for People Using Adult NHS Services. London: NICE, 2012 (https://www.nice.org.uk/guidance/ cg138/resources/patient-experience-in-adult-nhs-servicesimproving-the-experience-of-care-for-people-using-adultnhs-services-pdf-35109517087429) [Accessed January 8, 2020]

22. Ogrinc G, Davies L, Goodman D, Batalden P, Davidoff F, Stevens D: SQUIRE 2.0 (Standards for QUality Improvement Reporting Excellence): revised publication guidelines from a detailed consensus process. BMJ Qual Saf 25:986-992, 2016

23. Patel S, Bhatnagar A, Wear C, Osiro S, Gabriel A, Kimball $\mathrm{D}$, et al: Are pediatric brain tumors on the rise in the USA? Significant incidence and survival findings from the SEER database analysis. Childs Nerv Syst 30:147-154, 2014

24. Samuel N, Shamji MF, Bernstein M: Neurosurgical patients' perceptions of the "surgeon+": a qualitative study. J Neurosurg 124:849-853, 2016

25. Seifart C, Hofmann M, Bär T, Riera Knorrenschild J, Seifart U, Rief W: Breaking bad news - what patients want and what they get: evaluating the SPIKES protocol in Germany. Ann Oncol 25:707-711, 2014

26. Shiminski-Maher T: Physician-patient-parent communication problems. Pediatr Neurosurg 19:104-108, 1993

27. Teike Lüthi F, Cantin B: [Breaking bad news: "EPICES", a French style as a learning method.] Rev Med Suisse 7:85-87, 2011 (French)

28. Vermylen JH, Wood GJ, Cohen ER, Barsuk JH, McGaghie WC, Wayne DB: Development of a simulation-based mastery learning curriculum for breaking bad news. J Pain Symptom Manage 57:682-687, 2018

29. Wagner M, Mileder LP, Goeral K, Klebermass-Schrehof K, Cardona FS, Berger A, et al: Student peer teaching in paediatric simulation training is a feasible low-cost alternative for education. Acta Paediatr 106:995-1000, 2017

\section{Disclosures}

The authors report no conflict of interest concerning the materials or methods used in this study or the findings specified in this paper.

\section{Author Contributions}

Conception and design: Di Rocco, Zanello, Baugnon. Acquisition of data: Di Rocco, Zanello, Baugnon. Analysis and interpretation of data: Di Rocco, Zanello, Roux. Drafting the article: Di Rocco, Zanello, Roux. Critically revising the article: all authors. Reviewed submitted version of manuscript: all authors. Approved the final version of the manuscript on behalf of all authors: Di Rocco. Statistical analysis: Zanello, Roux.

\section{Supplemental Information \\ Online-Only Content}

Supplemental material is available with the online version of the article.

Supplementary Tables 1 and 2. https://thejns.org/doi/suppl/ 10.3171/2019.12.PEDS19554.

\section{Correspondence}

Federico Di Rocco: Hôpital Femme Mère Enfant, Hospices Civiles de Lyon and University Claude Bernard Lyon 1, Bron Cedex, France.federico.dirocco@chu-lyon.fr. 